\title{
A CONSTRUÇÃO DE OBJETOS DE DISCURSO NOS PERFIS FAKES DO TWITTER
}

\author{
Francisco Alves Filho* \\ Leila Rachel Barbosa Alexandre ${ }^{* *}$
}

Resumo: Neste artigo, tomando como pressuposto a ideia de que a referenciação é um processo discursivo levado a cabo durante a construção do texto (MONDADA; DUBOIS, 2003; KOCH, 2005; MARCUSCHI, 2008) e também o entendimento de que os gêneros do discurso, em função de suas particularidades retóricas e situacionais, exercem condicionamentos para os processos referenciais, objetivamos analisar algumas particularidades do processo de construcãa de objetos de discurso em postagens produzidas em perfis fakes do Twitter, estes caracterizados por assumir a lógica discursiva de uma celebridade e visarem provocar diversão e humor aos internautas. O corpus é composto por um exemplário de postagens que circularam em perfis fakes parodiando celebridades brasileiras e foram escolbidas em função da incidência mais evidente da construção referencial. Como resultado podemos afirmar que o fake tanto oferece o ponto de vista para a construção dos objetos de discurso mencionados nas postagens como é ele próprio tributário dessa construção.

Palavras-chave: Referenciação. Objeto de discurso. Perfil fake do Twitter.

\section{INTRODUÇÃO}

Neste artigo discutimos a interface referenciação e gêneros do discurso, visando compreender como o processo de construção de objetos de discurso ocorre num gênero específico. Para isso, tomamos como pressupostos as teses de que a referenciação é um processo discursivo levado a cabo pelos interlocutores durante os processos interacionais e de que gêneros de discurso particulares oferecem alguns condicionamentos para os processos referenciais. Em relação à noção de gêneros, apoiamo-nos na concepção sociorretórica de gêneros, que defende que os gêneros são formas de ação social tipificadas e associadas a situações também recorrentes e tipificadas (MILLER, 2009 [1984]; DEVITT'T, 2004; SWALES, 1990; CAMPBELL; JAMIESON, 1978).

\footnotetext{
* Professor Titular da Universidade Federal do Piauí - UFPI. Doutor em Linguística pela Universidade Estadual de Campinas - UNICAMP. E-mail: <chicofilhoo@gmail.com>.

** Professora da Universidade Federal do Piauí. Mestre em Letras - Estudos de Linguagem pela Universidade Federal do Piauí - UFPI. E-mail: <leilarachel@gmail.com>.
} 
Para este estudo, analisamos postagens dos seguintes perfis fakes (todos paródias de celebridades brasileiras): @ONiemeyer, @nairbello, @hebecamargo,@diImabr, @xuxaverde,@oclebermachado, @eike_batista_. Nas postagens colhidas desses perfis, analisamos, primordialmente, o tratamento dos objetos de discurso relacionados a referentes familiares ao parodiado, por acreditarmos que esses objetos de discurso são fundamentais para a construção de um gênero que é baseado na realidade de uma celebridade e que por isso precisa estar atento às pessoas e fatos com os quais ela se relaciona.

$\mathrm{Na}$ próxima seção, discutimos os pressupostos para uma abordagem retórica do gênero perfil fake do Twitter, enfatizando a centralidade das noções de propósito comunicativo e ação social; situamos o gênero perfil fake do Twitter no ambiente digital; e, em seguida, caracterizamos sociorretoricamente o perfil fake e as postagens nele inseridas. $\mathrm{Na}$ terceira seção do artigo, discutimos as inter-relações entre gêneros e referenciação, quando defendemos ser a referenciação um mecanismo ao mesmo tempo formal e substantivo fortemente ligado às práticas genéricas. Na quarta seção, detalhamos os procedimentos metodológicos utilizados para o desenvolvimento da pesquisa. As duas últimas seções do artigo são dedicadas diretamente à análise dos dados (postagens de perfis fakes do Twitter) e nelas defendemos duas ideias principais: primeiro, que o fake é o objeto de discurso central do perfil, o qual tanto é construído por intermédio de outros objetos de discurso presentes nas postagens como determina os modos como outros objetos de discurso são construídos; por fim, defendemos que o processo de referenciação dos fakes possui uma tripla ancoragem: nas narrativa fake de bastidores, no parodiado e nos fatos sociais.

\section{PRESSUPOSTOS DE UMA ABORDAGEM RETÓRICA DO GÊNERO PERFIL FAKE DO TWITTER}

É objetivo deste artigo fazer uma investigação acerca da construção de sentido via referenciação num corpus de um gênero de texto específico, qual seja o perfil fake do Twitter. Em função desta vinculação entre o processo de construção de sentido e sua presença num corpus particular, julgamos necessário caracterizar os modos de 
funcionamento deste gênero para que a análise da referenciação possa levar em conta as suas particularidades genéricas.

Comecemos pela noção de gênero, hoje tão alardeada mas nem sempre bem compreendida. Inicialmente, convém reconhecer que existem muitas vertentes teóricas sobre gêneros, as quais se diferenciam seja porque partem de pressupostos teóricos diferentes, seja porque visam objetivos analíticos diversos. Entretanto, embora diversificada, a noção de gênero de teorias mais recentes (sociorretórica, sociodiscursiva e sociointeracionista) deixa entrever uma recusa por visões formalistas e classificatórias e a adoção de concepções funcionais. Bakhtin (2003 [1979]), Miller (2009 [1984]), Devitt (2004), Marcuschi (2008), em essência, compartilham a tese de que os gêneros são adaptativos e flexíveis pelo fato de sua forma ajustar-se historicamente e culturalmente às funções comunicativas, retóricas e pragmáticas dos grupos sociais. $\mathrm{Na}$ síntese de Devitt (2004, p. 34), "os gêneros funcionam para um grupo de usuários da linguagem a fim de preencher as necessidades do grupo".

Mas é necessário reconhecer que o caráter funcional e flexível dos gêneros não os transforma em constructos semióticos desregrados ou que dependeriam do livre arbítrio de cada falante. O caráter funcional que preside os gêneros é de natureza essencialmente social e cultural, razão pela qual, mesmo em ambientes em que o uso da linguagem não recebe monitoração linguística e textual direta e sistemática (como é o caso das redes sociais na internet), as normas sociais que regulam os gêneros e a linguagem atuam claramente. Como veremos à frente, muitos gêneros surgiram na internet e mantêm uma série de características recorrentes.

\subsection{Ação social e propósito comunicativo}

Nos estudos retóricos de gêneros (como propostos por Miller 2009 [1984] e Devitt, 2004), a noção de ação social desempenha papel central na definição teórica de gêneros, já que se adota uma visão essencialmente pragmática, centrada naquilo que fazem os usuários quando usam os textos. $\mathrm{Na}$ formulação pragmático-retórica mais conhecida, Miller (2009 [1984], p. 34) defende que "os gêneros são ações retóricas tipificadas fundadas em situações recorrentes", com isso 
enfatizando que: a) os gêneros são essencialmente pragmáticos e retóricos; b) o seu pragmatismo é situacional, ou seja, é responsivo em relação às situações retóricas mas também a elas se integra; c) as ações, embora geridas mais comumente num plano individual, operam como tipificações de larga escala social. A formulação de Miller (2009 [1984]), inspirada nos trabalhos de Bitzer (1968), ao tempo em que elege o conceito de situação como central, parte para uma reformulação teórica de tal conceito, ao negar o seu caráter materialista, objetivista e idiossincrático e, em contrapartida, passa a defender sua natureza simbólica, intersubjetiva e recorrente. Miller entende que as situações nunca se repetem embora sejam percebidas, em grande parte, por inflexão das exigências sociais, como sendo semelhantes. Nisso temos um dos insights mais interessantes dos estudos retóricos de gêneros: não são apenas os textos que são tipificados; as próprias situações e as ações são concebidas, pelos usuários, como recorrentes e tipificadas. Por isso, em consonância com esta visão, o domínio de um gênero implica saber reconhecer uma situação como sendo de um determinado tipo e saber agir em acordo com esta situação (ou insurgir-se deliberadamente contra a situação, se for o caso).

A visão retórica e pragmática de gêneros teve como uma de suas consequências a adoção do conceito de propósito comunicativo como central para se proceder às análises de dados empíricos. $\mathrm{Na}$ formulação de Swales (1990, p. 58), "um gênero compreende uma classe de eventos comunicativos, cujos membros compartilham um conjunto de propósitos comunicativos". Em função disso, uma das tarefas do analista de gêneros é reconhecer quais propósitos comunicativos são acionados e compartilhados pelos usuários de dada comunidade linguística. Tal tarefa apresenta uma série de complicações, já apontadas por Askehave e Swales (2009 [2001]): nem todos os propósitos são explicitados textualmente (como é o caso, citado pelos autores, da lista de compras cumprindo o propósito de autodisciplinar o consumo dos compradores); vários propósitos, por vezes, coexistem e não são claramente distintos. Uma das alternativas metodológicas usadas para contornar tal dificuldade foi recorrer etnometodologicamente aos próprios usuários, solicitando deles relatos explicativos sobre as finalidades para as quais usam os gêneros em suas vidas. 
Neste estudo, embora não seja objetivo primordial investigar os propósitos comunicativos do perfil fake, importa levar em conta em que medida os propósitos comunicativos compartilhados pelos criadores dos fakes restringem e/ou possibilitam a construção dos objetos de discurso nas postagens. A questão que se coloca é: propósitos comunicativos largamente compartilhados pelos usuários de perfis fakes influenciam as operações sociocognitivas de construção dos objetos de discurso? Haveria algum tipo de condicionamento pragmático em relação aos processos referenciais? Ou os processos referenciais encontram-se num nível de generalização independente de condicionamentos pragmáticos e retóricos?

\section{$2.2 \mathrm{O}$ aplicativo $T_{\text {witter }}$ o surgimento de novos gêneros}

No ambiente digital têm proliferado muitos gêneros nas duas últimas décadas, seja pelo fato de que alguns gêneros antes existentes em outras mídias migraram para a internet, nela reacomodando suas exigências e propósitos, seja porque gêneros intrinsecamente digitais, como os que são ligados aos blogs (blog pessoal, blog jornalístico etc.) e ao Twitter (perfis fakes, perfis institucionais, perfis promocionais etc.), efetivamente surgiram e se desenvolveram pela primeira vez neste ambiente. Como salientou Miller (2009), é notável como no meio eletrônico, caracterizado por mudanças constantes e rápidas, tenham surgido gêneros, por vezes, com grande estabilidade genérica. Uma hipótese para explicar a recorrência nos gêneros digitais pode ser extraída do fato de que, dada a facilidade e rapidez para o compartilhamento de textos com contingentes enormes de pessoas, facilmente os usuários divulgam seus modos de agir através dos gêneros, proporcionando uma rápida difusão do agir prototípico. Ou seja, o acesso rápido e veloz a textos produzidos em muitos lugares diferentes destaca os usos acordados socialmente, facilitando a consolidação de recorrências genéricas.

O Twitter é um aplicativo para comunicação na internet criado para satisfazer a necessidade inicial de as pessoas compartilharem publicamente o que estão fazendo e de permanecerem em contato com amigos (ALEXANDRE, 2012; CASTRO, 2012). Além disso, o aplicativo 
Twitter é uma ferramenta tecnológica que tanto decorre da cultura da autoexposição e do exibicionismo e voyeurismo mediado (MILLER, 2009 [2004]), como contribui para que esta cultura se dissemine e se fortaleça. Não à toa que este aplicativo desenvolveu duas ferramentas específicas: as opções following e follower, as quais permitem aos usuários tanto seguirem como serem seguidos por outros usuários, remetendo às relações de admiração e fanatismo e à cultura de fãs (WILSON, 2011).

Do ponto de vista linguístico-textual, um traço característico do aplicativo Twitter é a restrição da quantidade de caracteres que pode ser usada em cada tuíte: apenas $140^{1}$. Tal restrição exige dos tuiteiros uma alta habilidade de síntese, ao tempo também em que produz atos comunicativos marcados pela rapidez e instantaneidade. Contudo, os próprios usuários começaram a fazer pressão para que fosse possível ultrapassar a restrição dos 140 caracteres sem ser preciso aumentar essa quantidade, o que propiciou o desenvolvimento de recursos como as hashtags, as quais tornam as postagens ainda mais concisas, possibilitando economia de espaço e facilitando acesso posterior a uma postagem por outros usuários (ALVES FILHO; ALEXANDRE; CASTRO, não publicado). Dessa forma, já há uma tradição no Twitter de criar conteúdos que não se limitam aos 140 caracteres das postagens, o que é feito através de links que conduzem os usuários para textos maiores em outros sites. Pesquisa de Castro (2012) evidenciou que os perfis institucionais de universidades e faculdades comumente criam postagem no mesmo formato de manchetes de jornais, tendo como função convidar o leitor para ler uma notícia completa que se encontra hospedada no site da instituição.

Embora haja estudos dizendo que o Twitter (enquanto aplicativo) é um gênero ou que os tuítes (as postagens) equivalem ao gênero, defendemos aqui posição diferente. Para nós, é necessário distinguir três fenômenos diferentes, embora interligados neste ambiente digital. Primeiro, há o aplicativo Twitter, um programa para uso em celulares e computadores caracterizado por um conjunto de affordances (uma combinação de restrições e de possibilidades técnicas). O aplicativo é

\footnotetext{
1 A restrição dos 140 caracteres decorreu do fato de o aplicativo Twitter ter sido desenvolvido para uso também em aparelhos de telefonia móvel, através de mensagens de texto, e nestes aparelhos, diferentemente dos editores de texto para computador, há uma limitação quanto ao número de caracteres para cada troca comunicativa.
} 
caracteristicamente tecnológico, tendo sido criado por uma equipe pequena de profissionais. Em segundo lugar, existem vários gêneros que são criados, atualizados e usados por intermédio do aplicativo Twitter, figurando entre eles o perfil pessoal, o perfil profissional e o perfil fake, para citar alguns. Cada uma destas modalidades de perfil é um gênero pelo fato de configurarem um conjunto de ações sociais recorrentes e reconhecidas pelas comunidades. Além do mais, os elementos formais e estruturais que compõem o perfil (imagem-símbolo, descrição do perfil, bio $^{2}$ e postagens) constituem um enunciado todo e indissolúvel, de modo que não se pode tomar os tuítes como independentes e desvinculados dos outros elementos que constituem o perfil. Por fim, em terceiro lugar, existem as postagens (os tuítes), elementos componentes dos perfis, cuja função é estabelecer interação direta com outros usuários. Em síntese, entendemos que os tuítes são um dos elementos que compõem a estrutura comunicativa dos vários gêneros existentes no aplicativo Twitter.

Do ponto de vista interacional, os perfis no Twitter caracteristicamente estabelecem interações em aberto, sem interlocutores pré-definidos. Ou seja, não se trata de uma interação privada, um a um, tal como pode ser realizada via e-mail. Usar o Twitter é buscar se comunicar com uma imensa rede de internautas, conhecidos e desconhecidos - de modo geral, os tuiteiros buscam atingir o maior número de pessoas. Neste sentido, os gêneros existentes no Twitter guardam semelhanças com os gêneros da comunicação de massa dos jornais e televisões, os quais necessitam atingir um público cada vez mais extenso.

\section{$2.3 \mathrm{O}$ perfil fake}

Alexandre (2012), apoiando-se nos Estudos Retóricos de Gêneros, especialmente em Miller (2009 [1984]) e Devitt (2004), defende que o perfil fake no Twitter é um gênero pelas seguintes razões: primeiro porque serve a exigências retóricas recorrentes na sociedade (entreter, produzir humor, difundir ideias, homenagear e criticar celebridades, criar e manter comunidade); segundo pelo fato de atender a uma exigência claramente social, qual seja:

\footnotetext{
${ }^{2}$ Bio é a descrição do perfil do tuiteiro, uma minibiografia feita em, no máximo, 160 caracteres.
} 
proporcionar entretenimento humorístico interessante no Twitter tanto para quem produz como para um público que quer conteúdo diferenciado e divertido, parodiando, para isso, a personalidade de pessoas e personagens famosos, considerando que estamos em uma sociedade que tem curiosidade pela vida desses indivíduos. (ALEXANDRE, 2012, p. 174).

Como se vê, não se trata de o perfil fake servir a propósitos inteiramente novos ou atender a uma exigência social inédita. O que lhe confere identidade genérica é o fato de haver uma combinação particular de propósitos, de conjunto de affordances e de uma fusão específica entre forma e substância. Com o perfil fake os criadores produzem humor, mas o fazem num ambiente digital particular e o fazem assumindo o ponto de vista discursivo de uma outra pessoa, baseado principalmente em celebridades. Como esclarece Alexandre (2012), a ação retórica recorrente no perfil fake proporciona entretenimento ao próprio criador do perfil, já que este brinca com a linguagem e com a situação fictícia, e também ao público seguidor, o qual acompanha o perfil, oferece feedback ao criador, entra no jogo fictício e, muitas vezes, explicita sua apreciação em relação às postagens.

Embora alguns internautas por vezes confundam-se e imaginem que os perfis fakes são verdadeiros em relação à pessoa parodiada, existem claros indícios nos perfis de que eles são uma paródia. Esses indícios são manifestados recorrentemente nas bios, as quais comumente expressam uma autodescrição que dificilmente seria enunciada pela própria pessoa real. É o caso dos elementos descritivos do perfil @a_marrom (uma paródia da cantora Alcione): "Sou a cantora maranhense mais famosa do mundo. E tenho um viaduto só meu. Morram". Dificilmente um perfil real se autodescreveria de modo egocêntrico e vaidoso, pelo fato mesmo de que isso poderia suscitar reações de antipatia e de críticas por parte dos seguidores. Ou seja, o jogo discursivo do perfil fake não é fazer os seguidores crerem que estão seguindo e interagindo com a celebridade real, mas, sabendo que se trata de uma ficção, divertir-se com enunciações e discursos possíveis e imaginários, segundo um ponto de vista que mescla a lógica discursiva do parodiado e a lógica discursiva do parodiador. Em outros casos, a bio explicitamente afirma que se trata de um perfil não oficial e parodiador, 
como é o caso do perfil fake da apresentadora de TV Hebe Camargo: "De Taubaté para o mundo! - Perfil não oficial", apenas uma paródia e homenagem a maior apresentadora do Brasil: contato: hebecamargobilionaria@gmail.com“. Já a bio do perfil fake (a)diImabr assim descreve a parodiada: "sou linda, sou presidente, sou Dilma. Sou uma sátira, se vc não sabe o que é sátira, pega o número na fila do Bolsa Família. Ouvidoria: dilmabolada@gmail.com“. E há ainda um elemento descritivo que indica o lugar onde o fake supostamente reside: Brasólia. Aqui há vários recursos para garantir que não se trata do perfil pessoal verdadeiro da presidenta: admissão de que se trata de uma sátira; excesso de vaidade; falta de polidez e expressão direta de ponto de vista sem meias palavras; e menção a um lugar inexistente (Brasólia).

\subsection{As postagens no fake}

Neste artigo, faremos a análise do processo de referenciação apenas das postagens pelo fato de estas serem atualizadas com grande frequência e serem o espaço textual de construção de pontos de vista sobre fatos do mundo, os quais necessariamente recorrem aos processos de referenciação. As postagens, por serem o espaço de atualização frequente do fake, recebem maior atenção por parte dos seguidores, os quais nutrem a expectativa de encontrarem lá sempre novidades. Além disso, o conjunto das postagens precisa apresentar coerência ao ponto de vista enunciativo do parodiado, de modo a tornar crível e verossímil o perfil. Ou seja, embora as postagens não tenham sido criadas pelo parodiado, elas necessitam ser coerentes entre si e em relação a uma ficção discursiva criada e acompanhada pelos seguidores. Essas postagens trabalham as características do parodiado, construindo um personagem próprio da ficção discursiva dos fakes, o que é feito

através da mescla criativa de realidade, exagero e invenção sobre a vida e as características do parodiado. Ao usar a fala e as características do parodiado aplicadas a outros contextos, essas postagens exploram, extrapolam e reconstroem as possibilidades

\footnotetext{
${ }^{3}$ Ênfase nossa.
} 
do parodiado dentro de uma narrativa Fake, tornando-o a base real de um personagem que é também fictício. (ALEXANDRE, 2012, p. 170)

Esse trabalho de construção de uma narrativa fake baseada na paródia é feito recorrentemente nas postagens analisadas por Alexandre (2012) com o uso de dados e acontecimentos envolvendo o parodiado (bordões, fatos de grande repercussão, frases famosas, estilo) e com a remissão a um imaginário popular acerca da vida desse parodiado. A partir dessas características de base real é produzido o conteúdo das postagens, que, segundo Alexandre (2012), recorrentemente aludem aos seguintes tópicos 4 :

Narrativa de bastidores (simulam acontecimentos supostamente ocorridos com o parodiado em sua vida privada):

Exemplo (1)

Hebe Camargo@hebecamargo 03 junho Cheguei agora em casa. Lelio vai me dar as contas...

Acontecimentos recentes envolvendo o parodiado:

Exemplo (2)

Xuxa Verde@xuxaverde 20 maio PREFERI NÃO FALAR DE COISAS COMO AMOR ESTRANHO AMOR, MARLENE MATTOOS E PACTO PRA NÃO CHOCAR FAMÍLIA BRASILEIRA \#XUXAREVELA ${ }^{5}$

Atualidades (comentários, notadamente jocosos, sobre os fatos do momento divulgados na mídia):

\footnotetext{
${ }_{4}^{4}$ Os dois primeiros tópicos também foram identificados por Wilson (2011) nas postagens dos fakes políticos australianos que ele pesquisou. Alexandre (2012) toma de empréstimo o termo "narrativa de bastidores" desse autor.

${ }^{5}$ Essa postagem foi produzida na época em que foi veiculada entrevista com a apresentadora Xuxa.
} 
Exemplo (3)

Dilma Rousseff@diImabr 31 maio Mandei Lulão mandar um beijo pra mim hoje no Ratinho. Vamos acompanhar! \#LulaNoRatinho

Interação com seguidores:

Exemplo (4)

Nair Bello@nairbello 28 maio Vou pensar. Ela me abandonou quando eu mais precisei. RT @amyntaamoon:@nairbello Você vai aceitar a Dayanna de volta, Nonna??

No decorrer deste trabalho, veremos que este conteúdo é veiculado nas postagens dos perfis fakes de acordo com estratégias discursivas específicas, com foco no processo de referenciação, que nos mostrará como são construídos preferencialmente os objetos de discurso nesse gênero através das postagens.

\section{GÊNEROS E REFERENCIAÇÃO}

Ao entendermos gênero como ação social, assumimos também que para que essa ação social seja empreendida é necessário que o gênero seja materializado em textos, que efetivamente circularão em sociedade. É nos textos que se realiza uma parte mais visível dos gêneros — as configurações de forma e conteúdo — guiada pelas exigências que o gênero tem que atender. Frequentemente, formas e conteúdos específicos em um texto nos fazem reconhecer de que gênero ele participa, como quando vemos "Era uma vez..." no começo de um texto e o identificamos com o Conto de Fadas. No entanto, esses elementos formais não são diretamente responsáveis pela construção do gênero, mas resultam da construção dele. Ou seja, esses elementos servem ao gênero por conta da necessidade de estruturas retóricas nos textos que ajudem as pessoas a atenderem exigências situacionais tipificadas (DEVITT, 2004; CAMPBELL; JAMIESON, 1978). 
Como Miller (2009 [1984]) argumenta, forma e conteúdo de um gênero são elementos interdependentes, já que o conteúdo (substância), formado pelo significado construído nas práticas sociais, é simbolizado de maneiras específicas na forma, que instancia a substância e instrui as pessoas a como lidarem com ela. A forma, portanto, porta significado social, porque reflete aspectos situacionais, ideológicos, culturais e intencionais vigentes em uma sociedade, ao ser unida ao conteúdo. Nem forma nem conteúdo são, assim, aleatórios nos textos, já que eles são motivados socialmente e, principalmente, pelos gêneros a que servem. São convenções que se estabelecem nos textos, mas que são mutáveis, podem ser reconstruídas, transformadas, a depender das suas motivações genéricas.

Dentre os elementos formais/substantivos que servem ao atendimento de exigências retóricas pelos gêneros, enquadra-se a referenciação, que, como defendido em trabalhos anteriores (ALVES FILHO; SILVA; ALEXANDRE, 2011a, 2011b; ALEXANDRE, 2010), é fortemente ligada às práticas genéricas. Entendemos a referenciação, baseando-nos em Mondada e Dubois (2003), como o processo em que objetos de mundo são transformados em objetos de discurso através das práticas sociais dos sujeitos, que estabilizam o mundo através de categorias no discurso. Tomando as ideias sobre fabricação da realidade de Blikstein (2003) e relacionando-as às de Mondada e Dubois (2003), podemos dizer que os objetos de mundo são atravessados pelos "óculos sociais", pela visão de mundo que as pessoas trazem de sua vivência em sociedade, de sua práxis, sendo transformados em referentes. Esses referentes não são o real puro, mas o real visto pela ótica de nossa visão sociocognitiva, uma versão discretizada do real, uma realidade fabricada pela práxis. Nesse sentido é que podemos dizer que não temos acesso a todas as dimensões físicas e psicológicas de um ser do mundo: só temos acesso aos papeis sociais que esse ser desempenha, enquanto referente fabricado pela práxis. E são os referentes que podem ser transformados em objetos de discurso, sendo recortados pela língua segundo facetas sociais específicas que estejam em foco em um processo discursivo específico.

Quando, por exemplo, vai se falar de uma pessoa em um texto específico, não falamos dela em si, como um ser material do mundo, mas de um referente já apreciado, já atravessado por valorações, visto 
segundo uma práxis e, dependendo dos propósitos de sentido que desejamos alcançar e do gênero de texto em que a fala sobre esse referente vai ser veiculada, são recortadas facetas específicas desse referente. Assim é que, como mostramos em Alves Filho, Silva e Alexandre (2011b), em um gênero como a notícia policial, tal como veiculada em jornais piauienses, pessoas envolvidas em fatos policiais já são previamente apreciadas socialmente, de forma que há uma divisão de papeis entre criminosos e policiais. No caso do referente policial constituído pelas práticas sociais, o que vai recorrentemente para os textos desse gênero é um objeto de discurso que indica um papel profissional marcado pela competência, obediência a um poder hierárquico devidamente constituído, que deve ser posto em destaque, sendo, nesse caso, marcado com descrições nominais formadas por artigo indefinido mais patente policial mais nome próprio, guiando, assim, a atenção do leitor para "o status profissional e para a atuação daquele policial específico que representa determinado Distrito Policial, ficando o fato ocorrido em segundo plano" (ALVES FILHO, SILVA, ALEXANDRE, 2011b, p. 99).

Nesse sentido, é importante salientar os estudos de Koch (2005), que mostram que a apresentação do objeto de discurso pode ocorrer a partir de descrições nominais, as quais ativam conhecimentos compartilhados pelos interlocutores de traços desse objeto de discurso introduzido por uma descrição nominal. Esse processo também é visto em Maingueneau (2001), ao dizer que tanto os grupos nominais introduzidos por artigos como os nomes próprios dos referentes no mundo realizam a relação entre referente mundano e objeto de discurso, mas que o nome próprio designaria o próprio referente mundano, já as descrições nominais retomariam apenas indiretamente esse referente. Maingueneau (2001) ressalta ainda que, para que o nome próprio cumpra o seu papel de designar diretamente o referente, deve ser compartilhado pelo coenunciador.

Frisamos, no entanto, que mesmo que o nome próprio represente um ato de batismo, estabilizado em uma determinada comunidade, ainda assim não há uma relação direta entre o referente mundano e o objeto de discurso, pois, tomando as ideias de Bakhtin (1997 [1929/1930]), podemos dizer que há sempre uma luta incessante de valores quando os discursos são produzidos. Isso porque a palavra usada no discurso não 
terá o sentido objetivo, dicionarizado ou de batismo, mas sim uma carga apreciativa influenciada pelo andamento e propósitos de um discurso que se realiza através de um gênero.

A referenciação é, de fato, relacionada às práticas sociais de maneira mais ampla, mas os processos referenciais se manifestam em textos, que participam de gêneros, que, por sua vez, são sensíveis às variações de práticas sociais específicas. Isso nos leva a entender que o gênero imprime práticas sociais específicas aos elementos textuaisdiscursivos que se relacionam a ele, práticas essas relacionadas a uma visão de mundo da sociedade onde esse gênero circula e à situação retórica específica que ofereceu a exigência a que o gênero deveria atender. Acreditamos, portanto, que o processo de referenciação visível em um texto é fortemente influenciado por práticas sociais específicas que contribuem para o uso de um gênero, ajudando-o a atender a uma exigência retórica. Sendo assim, por ser intrinsecamente relacionada a uma prática genérica, vemos também a referenciação como um processo sujeito à tipificação, à recorrência, que se faz de maneira parecida em textos que participam de um mesmo gênero porque precisam ajudá-lo a resolver exigências sociais parecidas.

\section{PROCEDIMENTOS METODOLÓGICOS}

Iniciamos nossa pesquisa a partir da escolha dos perfis fakes que forneceriam postagens para nossa análise. Essa escolha se deu com base em listas ${ }^{6}$ de "melhores fakes do Twitter" que circulam na internet, sendo motivada pelo interesse em trabalhar com perfis que, por serem considerados como os melhores por publicações especializadas, podiam refletir interesses e gostos do público que segue perfis fakes no Twitter, revelando uma prática mais estabilizada de fazer perfis, com características específicas que sejam eficientes para agradar esse público. Além disso, o sucesso desses perfis é espelhado pela grande quantidade de seguidores ${ }^{7}$ que possuem: @ONiemeyer (31.631 seguidores),

\footnotetext{
${ }^{6}$ Nos baseamos principalmente nas seguintes listas: http://www.tecmundo.com.br/twitter/21474os-12-melhores-fakes-do-twitter.htm

http://www.techtudo.com.br/rankings/noticia/2012/03/top-10-fakes-no-twitter-que-valem-penaseguir.html. Essas listas foram tomadas como base por estarem vinculadas a dois sites que são referência em publicações no Brasil sobre novidades em tecnologia e meio digital.

${ }^{7}$ Números atualizados em 13/10/2012.
} 
@diImabr (63.054 seguidores), @oclebermachado (242.786 seguidores), @eike_batista_(13.499 seguidores), @nairbello (122.350 seguidores), @ hebecamargo (66.930 seguidores), @xuxaverde (48.520 seguidores).

O tipo de fake mais característico do Twitter é o parodístico e, dentro desse subtipo, o de celebridades. Há forte presença de fakes no Twitter que parodiam celebridades que desempenham papéis em programas de TV, sendo essas as celebridades típicas, mas há também vários perfis que parodiam celebridades relacionadas a outros campos de atividade. Tendo esse fato em vista, escolhemos, dentre os vários perfis citados nessas listas, sete que refletem caracteristicamente essa situação. Assim, temos em nossa análise perfis relacionados a celebridades da programação televisiva (das áreas de teledramaturgia, programas de auditório e jornalismo esportivo) e a celebridades advindas de outras classes profissionais, que não são trabalhadores da mídia televisionada (embora possam estar frequentemente em foco nesse meio). No caso dos perfis que escolhemos, esse grupo é formado por parodiados representantes da classe política, da classe empresarial e da classe dos profissionais de arquitetura. Essa escolha se deu numa tentativa de contemplar, pelo menos em parte, a diversidade das atividades dos parodiados, o que nos permitiu verificar de forma mais eficiente as recorrências nos processos de referenciação dos perfis fakes como algo relacionado de fato ao gênero e não apenas a exemplares particulares de fakes que parodiassem tipos de celebridades específicos.

Após definirmos os perfis fakes que forneceriam os dados para nossa pesquisa, coletamos postagens veiculadas por eles de maio a julho de 2012, nas quais pudemos observar as tendências nos processos referenciais que descrevemos nas próximas seções deste artigo. Focamos nossa observação nas postagens que mencionavam ou se reportavam a referentes relacionados ao parodiado, já que esse tipo de postagem é a mais característica dos perfis que têm como base uma paródia e é também um dos elementos mais importantes na construção do personagem fake, ao fazer a ponte entre a ficção construída pelo fake e a realidade que é relacionada ao parodiado. De todas as postagens observadas durante esse período, trouxemos a análise de 14 para este artigo, sendo essas postagens representativas dos processos referenciais realizados recorrentemente nos perfis fakes analisados. 


\section{O FAKE: UM OBJETO DE DISCURSO QUE CONSTRÓI E É CONSTRUÍDO POR OUTROS OBJETOS DE DISCURSO}

Ao estudarmos o processo de referenciação nos perfis fakes, importa-nos entender, principalmente, os pressupostos requeridos do leitor para entender os textos que participam desse gênero e, consequentemente, para saber lidar com objetos de discurso aí construídos. Como dito anteriormente, a referenciação ajuda estrategicamente o gênero a atender a exigências retóricas ao mesmo tempo em que o entendimento do gênero ajuda as pessoas a processarem os textos e seus objetos de discurso. Nesse caso, é necessário analisar quais características do gênero Perfil fake influenciam na constituição de um processo de referenciação específico presente em seus tuítes, assim como é preciso perceber esse gênero como um frame que orienta o entendimento dos objetos de discurso construídos nos tuítes.

A base da paródia dos perfis fakes não é simplesmente uma pessoa, mas um referente que é alguém famoso em determinada sociedade, que é visto sob certos olhares apreciativos e cercado por um imaginário coletivo acerca do seu trabalho e, principalmente, da sua intimidade. Nós não temos acesso a toda a vida dessa pessoa, a tudo o que ela é no mundo, mas apenas enxergamos aquilo que os nossos óculos sociais permitem e possibilitam. Sendo assim, defendemos que, quando são parodiados nos perfis fakes, esses referentes têm um de seus papéis sociais selecionado e trabalhado na linguagem dos tuítes, tornando-se, eles próprios, objetos de discurso. Embora haja um processo ficcional na construção do personagem fake, ele é em grande parte ancorado na realidade do referente que parodia. Nesse caso, o objeto de discurso (o personagem fake) construído nesses perfis é basicamente focado em uma caricatura de características marcantes da celebridade e de fatos engraçados ou estranhos que a envolvam.

Ao considerarmos que o personagem fake construído nos perfis que estudamos não é um referente empírico mas um objeto de discurso baseado em um referente que é parodiado por ele, estamos dizendo que esse personagem só existe enquanto elemento construído nas práticas discursivas desses perfis. Ele não preexiste no mundo real como uma entidade independente (como são, de fato, os parodiados), mas depende 
de uma construção feita com e na linguagem. Essa construção do fake na linguagem é feita, em grande parte, através das postagens que são, elas próprias, veiculadoras de objetos de discurso específicos.

Ao lermos as postagens de perfis fakes, temos a impressão de que o personagem fake é quem constrói as postagens no perfil, parecendo ser diretamente responsável pela forma como os objetos de discurso se desenvolvem nessas postagens, assim como acontece na maioria dos outros tipos de perfis. No entanto, o perfil fake parodístico é uma construção de um produtor que fez escolhas delimitadas sobre quais características reais do parodiado ele iria trabalhar e quais características seriam exageradas. Sendo um objeto de discurso bem delimitado, o fake já é restrito em seu papel social, portanto suas "opiniões" e "vivências" já aparecem no processo de referenciação sob uma ótica particular, porque o personagem é sujeito aos projetos de dizer do produtor do perfil.

Pensemos em um texto que participe do gênero conto: as diversas maneiras como os objetos de discurso são construídos e reconstruídos no decorrer da narrativa são escolhas feitas pelo produtor do texto, embora muitas vezes pareça que são construções feitas diretamente pelo narrador ou pelos personagens. O que acontece, tanto no conto como no fake, é que, ao dar voz aos personagens (eles próprios objetos de discurso construídos no decorrer do texto), o produtor do texto dá vida a eles, permite que eles vivam dentro da narrativa ficcional que é construída, embora essa vida seja um tanto delimitada, modelada, projetada.

Nas narrativas literárias, de um modo geral, os próprios personagens, além de serem objetos de discurso, também são produtores de discurso e constroem objetos de discurso de acordo com suas características específicas enquanto personagens, algo que também acontece com os fakes, que parecem falar através das postagens. Isso implica dizer que o modo como se dá o processo de referenciação associado a personagens específicos está a serviço de um projeto de dizer do texto como um todo e, mais especificamente, de uma construção das próprias personagens. Assim parece ser também o caso dos fakes, em que os referentes transformados em objetos de discurso sob a ótica do fake, assim como os demais processos discursivos que se desenvolvem nesses 
perfis, ajudam na construção do próprio objeto de discurso fake, legitimando suas características.

No caso dofake@diImabr, por exemplo, a partir do referente Dilma, presidenta da república, e de algumas de suas características reais ou que as pessoas costumam associar a ela, é feita uma paródia que se faz através de um objeto de discurso construído, dentre outras características, como uma presidenta dura, às vezes sem paciência, mas carinhosa, vaidosa, segura, que adora a cor vermelha, que tem muitos fãs, que acha que deveria ser rainha do Brasil. Essa imagem é construída, em grande parte, através das maneiras como o fake fala de si e de outros objetos de discurso nas postagens. E, diante desse quadro, os referentes mencionados em suas postagens serão objetos de discurso construídos e apreciados sob a perspectiva dessas e de outras características que delimitam o fake, como podemos visualizar nos exemplos a seguir:

Exemplo (5)

Dilma Rousseff @diImabr 31 maio Eu não vou estar forte para a reeleição. EU SOU FORTE! Sou linda, sou diva, sou Presidenta, sou Dilma! \#dilmais

Exemplo (6)

Dilma Rousseff@diImabr 31 maio Tomara que não mostrem minhas fotos antigas com o brother Lulão. \#LulaNoRatinho

No exemplo (5), a Dilma fake fala de si como alguém seguro de quem é e de seu poder, e essa percepção pode ser vista em diversas postagens, revelando que esse é um traço do personagem fakee. Já no exemplo (6), ela fala de um outro referente relacionado a ela, o expresidente Lula, que é designado como "brother Lulão", evidenciando uma construção do objeto de discurso em questão como um parceiro e um amigo tão íntimo que permite que seja chamado por esse grau de informalidade, o que remete à parceria que a parodiada Dilma realmente tem com Lula. Essa influência das características do fake sobre a construção dos objetos de discurso nas postagens será mais analisada a seguir. 


\section{A TRIPLA ANCORAGEM DO PROCESSO DE REFERENCIAÇÃO DOS FAKES}

Como já vimos, os conteúdos preferencialmente veiculados nas postagens dos perfis fakes consistem em narrativas de bastidores, comentário de fatos acerca do parodiado e comentário de atualidades, muitas vezes em tempo real. Esses tipos de conteúdos revelam que os perfis fakes recorrem fundamentalmente a uma ancoragem tríplice de seu sentido: no parodiado, na narrativa fake e na realidade social. Essa ancoragem tríplice perpassa todo o gênero e isso acontece também, como veremos nesta seção, em relação à construção dos objetos de discurso feita nos textos que participam desse gênero.

As postagens desses perfis nos mostram que, para entender satisfatoriamente as postagens e os referentes que ali estão sendo construídos como objetos de discurso, é necessário ter conhecimento de mundo, conhecimento da narrativa fake e conhecimento da própria vida do parodiado. O fake faz um jogo entre ficção e realidade que é capaz de trazer referentes do mundo real para uma narrativa ficcional e transformá-los em um objeto de discurso com características e apreciações subvertidas em relação ao que se conhecia. Além disso, são construídos objetos de discurso que só têm existência de fato enquanto parte da narrativa fake.

Ao observarmos as postagens dos fakes, percebemos que os objetos de discurso que remetem a pessoas próximas ao parodiado são designados com nomes próprios, sem muita explicação sobre o papel daquela pessoa na vida do parodiado, como se já fossem conhecidos. Essa característica da referenciação nas postagens é cara ao gênero perfil fake, que trabalha com a pressuposição de que os fatos e pessoas a que aludem já são conhecidos do público, o qual se interessa pelo perfil em grande parte porque se interessa pelo parodiado ou o conhece em algum grau.

Essa pressuposição de conhecimento partilhado é necessária, inclusive, para recuperar o humor implícito em várias postagens, que, se fossem veiculadas em outro tipo de perfil, não teriam tanta graça porque não estariam vinculadas à narrativa fake. Muitas postagens veiculadas nos perfis fakes são parecidas com outras postagens humorísticas que 
circulam em diversos tipos de perfis no Twitter, e fazem humor usando recursos semelhantes, no entanto, o diferencial das postagens dos perfis fakes é trazer a voz e as crenças do personagem fake para essas postagens, fazendo com que as pessoas imaginem que ele (ou o parodiado) são responsáveis por aquela produção de conteúdo. Assim, construções e referentes já conhecidos são atualizados na narrativa fakee, que funciona como um frame para o sentido e o humor dessas postagens e dos referentes a que elas remetem. Esse é o caso da seguinte postagem:

Exemplo (7)

Dilma Rousseff@diImabr_11 Jul Só pepino hoje no trampo.... tá fogo!

O exemplo (7) traz uma postagem que poderia ser veiculada em qualquer perfil pessoal para expressar um dia difícil de trabalho. No entanto, ao ser colocada no contexto do universo fake da @diImabr, torna-se engraçada, por permitir imaginar a presidenta da república se referindo às atividades do seu cargo como "trampo".

É importante ressaltar, no entanto, que a forte necessidade de conhecimento compartilhado para reconstruir os objetos de discurso presentes nas postagens dos fakes não é advinda totalmente de características do gênero. Embora, de fato, o gênero influencie fortemente o processo de referenciação, acreditamos que o conjunto de affordances a que esse gênero está vinculado pode ter seu papel nessa dinâmica, como nos mostram as postagens de perfis fakes analisadas. Como as postagens do Twitter têm um limite de 140 caracteres, torna-se importante que o máximo de informações possível seja condensado na mesma postagem, evitando assim a quebra de uma sequência textual do mesmo conteúdo em vários tuites. Ou seja, embora, em tese, alguém pudesse escrever um tuite em várias etapas, através de várias postagens, isso não tem ocorrido. A fim de escapar das restrições dos 140 caracteres, são usados recursos como hashtags, que podem marcar uma postagem de forma que identifique seu conteúdo com poucos caracteres, e links, que permitem que algo mencionado em uma postagem possa ser desenvolvido ou visualizado em outras partes da web. Ao lado desses dois recursos, a forma de construir os objetos de discurso nas postagens 
do Twitter também revelam uma preocupação com a condensação de conteúdo, o que acaba acarretando uma necessidade de cooperação maior do interlocutor para recuperar os sentidos do texto, já que as informações materializadas no texto passam a ser baseadas em implícitos, em menção a referentes como se eles já fossem conhecidos e em pouca explicação detalhada sobre os referentes mencionados.

Lembramos que o recurso à condensação de conteúdo não é exclusivo dos fakes, sendo frequentemente praticado em diversos outros gêneros que estão sujeitos às affordances do Twitter. No entanto, os textos que participam do perfil fake fazem essa condensação de conteúdo de forma a atender aos interesses do gênero.

\section{Exemplo (8)}

Eike@eike_batista_26 maio Comprei o Detran! Agora o Thor já pode dirigir.

No exemplo (8), são ativados dois objetos de discurso, Detran e Thor, que, se tomados isoladamente, não permitem recuperar todo o significado que adquirem tanto dentro do contexto fake quanto dentro de um contexto social mais amplo. Primeiro é necessário que se saiba que Thor é o nome do filho do empresário Eike Batista, parodiado pelo perfil em questão. Em seguida, face à menção ao referente Detran, é preciso acessar o conhecimento de mundo que dê conta da informação de que Thor teve seu direito de dirigir suspenso por se envolver em um grave acidente. Além disso, há ainda outra característica importante sobre o parodiado que deve ser lembrada: Eike Batista é um dos homens mais ricos do mundo. Todas essas ativações se relacionam ao parodiado e aos acontecimentos sociais, mas ainda é preciso que se conheça o andamento da narrativa desse perfil fake especificamente que, dentre outras características, traz um personagem que é vaidoso quanto à sua riqueza, que adora falar de suas posses e do quanto é rico. Ao acessar todos esses conhecimentos, torna-se mais completo o entendimento de que o personagem fake é um homem tão rico que pode comprar o Detran para que o filho possa ter o direito de dirigir novamente e ainda dá a entender que só assim ele conseguiria esse direito. 
Como os fakes são baseados em pessoas famosas, é comum que muitos dos referentes mencionados nas postagens sejam relacionados à realidade do parodiado, como é possível ver no exemplo (7) e nos exemplos a seguir:

Exemplo (9)

Xuxa Verde@xuxaverde 19 maio TO ACHANDO QUE ESSE NEGÓCIO DE SALXUXA, POMPOM E COMPETIÇÕES BABACAS ENTRE MENINOS E MENINAS NÃO ESTÃO COM NADA, PRECISO DE ALGO MELHOR

Exemplo (10)

Oscar Niemeyer@ONiemeyer 15 maio Instalaram Autocad no meu laptop para eu projetar no hospital. Só se esqueceram que eu ODEIO AUTOCAD! Meu negócio é papel e nanquim!

No exemplo (9) são mencionados os objetos de discurso "salxuxa", "pompom", "competições entre meninos e meninas", todos relacionados ao universo da apresentadora Xuxa. Já o exemplo (10) fala de "Autocad", "papel e nanquim", "hospital" e traz o verbo "projetar", expressões que remetem ao arquiteto Oscar Niemeyer, que na época em que foi feita essa postagem se encontrava hospitalizado.

Todas essas postagens trazem objetos de discurso ancorados na realidade do parodiado. A peculiaridade nesse caso é que, ao mencionar um referente do universo do parodiado, esse referente é trazido como objeto de discurso para a narrativa fake. Isso implica que esse objeto de discurso passa a ser recategorizado de diferentes formas de acordo com o andamento da narrativa fake, sem que isso espelhe uma mudança em sua designação. Conhecer a narrativa de bastidores típica de um fake é importante para entender o que esperar do tratamento dos objetos de discurso mencionados por ele. É preciso conhecer a faceta do fake que está em foco e entrar nesse jogo discursivo, entendendo que as visões do personagem serão delimitadas de acordo com seu projeto de dizer. No exemplo (9), os referentes relacionados a Xuxa são apreciados de forma 
negativa, seja explicitamente na descrição nominal "competições babacas entre meninos e meninas", seja pela menção de que esses elementos "não estão com nada" e que ela precisa de algo melhor. São apreciações que não se espera que a própria parodiada expresse abertamente, mas são relacionadas a ela por esses objetos de discurso familiares que são mencionados pela voz do fake.

A postagem do@ONiemeyer também traz uma ancoragem na realidade do parodiado, com elementos que remetem a sua profissão e a sua condição de saúde, mas esses elementos, mesmo apresentados sem modificadores, são apreciados sob a ótica do fake, sendo transportados para uma narrativa que, ao mesmo tempo em que reflete, também refrata a realidade. Isso se revela, em parte, quando percebemos que o fake aprecia negativamente o objeto de discurso "Autocad", que remete a um programa de computador bastante usado por arquitetos, em contraposição com "papel e nanquim”, deixando claro que é alguém que prefere trabalhar à moda antiga. Também vemos a relação distorcida entre realidade do parodiado e ficção fake quando, ao acessar a realidade, temos em mente que o parodiado possui saúde debilitada e idade muito avançada, mas, ao nos remetermos à narrativa fake, somos apresentados a um Oscar Niemeyer que usa laptop no hospital, projeta e parece bastante disposto. Esse jogo entre semelhanças e diferenças entre realidade e ficção acaba sendo um dos responsáveis pelo humor da postagem, ao permitir imaginar o parodiado em situações inusitadas, embora relacionadas a ele.

Mesmo nos casos em que são mencionados apenas os nomes próprios de pessoas relacionadas ao parodiado, sem qualquer outro modificador, não é possível dizer que esse nome apenas designa um referente do mundo, sem lançar-lhe quaisquer outras apreciações ou categorias. Vejamos alguns exemplos:

\section{Exemplo (11)}

Nair Bello@nairbello 27 maio artigo fakes referenciação/Nair Bello (nairbello) no Twitter_files/Nair Bello (nairbello) no Twitter.htmA Lolita ligou aqui em casa e ficou discutindo comigo. OLHA, eu saio do sério com gente que não entende o que eu estou falando 
Exemplo (12)

Pensador do Século@oclebermachado 11 julho Caio me confessou que ficou revoltado com os comentários de Sonnen. De tanta raiva, tomou até leite sem chocolate.

No exemplo (11), o objeto de discurso Lolita remete à atriz Lolita Rodrigues, que era amiga de Nair Bello. Esse objeto de discurso não só permite acessar o referente, mas é construído sob uma ótica da narrativa fake e recategorizado como "gente que não entende o que estou falando”. Já no exemplo (12), o objeto de discurso Caio, que remete ao comentarista de futebol Caio Ribeiro, embora apareça designado apenas pelo primeiro nome, sofre uma recategorização e é apreciado valorativamente como "bom moço", em uma interpretação autorizada pelas pistas textuais fornecidas no predicado, que menciona que, em um momento de raiva, tomar leite sem chocolate (e não outra atitude mais violenta) é considerada uma atitude de revolta por parte do parodiado. Percebamos que, ao fazer a designação do objeto de discurso apenas com o nome próprio (e, mais ainda, apenas com o primeiro nome), o produtor da postagem simula uma situação de familiaridade entre o personagem fake e o referente designado. Nesse caso, a apreciação e a recategorização dos objetos de discurso são feitas na predicação, como já previsto em Alves Filho e Vieira (2011).

Com a menção a um nome próprio de uma pessoa relacionada ao parodiado nas postagens do fake, o produtor do perfil ativa o universo do parodiado, que é a base do personagem fake, e confere verossimilhança a sua narrativa, baseada na realidade do parodiado. No entanto, o objeto de discurso designado pelo nome próprio nas postagens passa a ser regido pelo andamento da narrativa fake, mesmo que isso signifique refratar fortemente a realidade do referente comumente associado a esse nome próprio, como nos exemplos a seguir:

Exemplo (13)

10 julho Dilma Rousseff@diImabr Carminha está bolada com a Nina pelo mesmo motivo que estou com a Marcela Temer: empregada que tenta agradar demais e começa a abusar. 
Exemplo (14)

4 Jul Xuxa Verde@xuxaverde SASHA ABRIU A JANELA PRA GRITAR PELA VITORIA DO CORINTHIANS. ATIREI UM TUBO DE MONANGE NA NUCA DELA, PRA APRENDER A NÃO SER MALOQUEIRA

$\mathrm{Na}$ postagem do exemplo (13), o objeto de discurso Marcela Temer (esposa do vice-presidente), relacionado ao universo da parodiada, é construído, basicamente, como uma empregada doméstica da presidenta, sendo colocado em um papel social bastante diferente do que é comumente relacionado ao referente Marcela Temer. Esse estranhamento ou quebra de expectativa na construção do objeto de discurso acaba sendo um desencadeador de humor. Algo parecido acontece no exemplo (14), que representa uma situação frequentemente mencionada no perfil fake@xuxaverde, em que o objeto de discurso designado como "Sasha", e que remete à filha da apresentadora Xuxa, apanha da mãe para ser disciplinada. Essa é uma situação inusitada se buscarmos ancoragem apenas no real, mas faz sentido dentro da narrativa fake que é construída. Isso acontece não só com nomes próprios relacionados ao parodiado, mas também com fatos que aconteceram ou que as pessoas imaginam que tenham acontecido com o parodiado. Todos esses elementos são atualizados na narrativa fake ao mesmo tempo em que legitimam o perfil como paródia.

\section{CONSIDERAÇÕES FINAIS}

$\mathrm{Na}$ análise que fizemos da referenciação e dos objetos de discurso nos perfis fakes do Twitter foi possível flagrar algumas tendências quanto aos procedimentos textuais/discursivos de construção referencial associados às estratégias de leitura das postagens.

A primeira tendência diz respeito ao fato de o fake ser, ao mesmo tempo, construído pelos objetos de discurso presentes nas postagens e servir como ponto de vista para a construção destes objetos de discurso. A segunda tendência aponta para o fato de que o processo de compreensão das postagens depende intensamente de conhecimento compartilhado sobre o perfil real do parodiado, sobre as características 
eleitas para construir o perfil fake e sobre acontecimentos ligados à narrativa de bastidores envolvendo o fake. Os objetos de discurso mencionados nas postagens vinculam-se a narrativas de bastidores, a comentários de fatos acerca do parodiado e a comentários de atualidades, mas tudo é feito buscando imprimir humor e divertimento ao criador do fake e a seus seguidores.

Restrições e possibilidades específicas do gênero perfil fake, como a restrição dos 140 caracteres, oferecem alguns condicionamentos para o referenciação nele construída, destacando-se a apresentação de objetos de discurso novos nas postagens como se fossem já dados e conhecidos dos seguidores e o reenquadramento de referentes vistos, muitas vezes surpreendentemente, pela ótica do parodiado. Como uma das ações retóricas centrais deste gênero é proporcionar humor e divertimento aos seguidores, a elaboração do humor vale-se de estratégias de construção de objetos de discurso segundo um ponto de vista inesperado para o parodiado, embora possível em certas circunstâncias.

\section{REFERÊNCIAS}

ALEXANDRE, L. R. B. O Perfil Fake como um gênero do Twitter. 2012. 193 f. Dissertação (Mestrado em Letras) - Centro de Ciências Humanas e Letras, Universidade Federal do Piauí, Teresina, 2012.

- A influência do gênero na referenciação: o caso da Carta ao Leitor. In: SIMPÓSIO INTERNACIONAL DO NÚCLEO INTERDISCIPLINAR DE ESTUDOS DA LINGUAGEM, Recife, 2010. Anais Eletrônicos... Recife: Editora Universitária da UFRPE, 2010. Disponível em: http://www.nielufrpe.com.br/siniel-anais-eletronicos.html.

ALVES FILHO, F.; CASTRO, B. D. R.; ALEXANDRE, L. R. B. \#Marcarporque - funções sócio-retóricas das hashtags no Twitter. [artigo não publicado].

ALVES FILHO, F.; SILVA, L. dos S.; ALEXANDRE, L. R. B. Relações de imbricação entre gêneros do discurso e referenciação no Jornal Folha de S. Paulo. Veredas, Juiz de Fora, v. 15, n. 1, p. 222-237, 2011a. Disponível em: <http://www.ufff.br/revistaveredas/files/2011/05/ARTIGO-161.pdf>.

. Acima dos fatos, a polícia: o nome próprio como marcador da promoção policial nos jornais piauienses. In: COSTA, C. de S. S. M. da; LIMA, M. A. F. (Orgs.). Nas trilhas da linguagem: pesquisa e ensino. Teresina/Rio de Janeiro: EDUFPI/Booklink, 2011b. p. 85-105. 
ASKEHAVE, I; SWALES, J. M. Identificação de gênero e propósito comunicativo: um problema e uma possível solução. In. BEZERRA, B. G.; BIASI-RODRIGUES, B.; CAVALCANTE, M. M. (Orgs.). Gêneros e sequências textuais. Recife: Edupe, [2001] 2009. p. 221-247.

BAKHTIN, M. Os gêneros do discurso. In: . Estética da criação verbal. São Paulo: Martins Fontes, [1979] 2003.

. Marxismo e filosofia da linguagem. São Paulo: Anna Blume/Hucitec, 1997 [1929/1930].

BITZER, L.F. The rhetorical situation. Philosophy and Rhetoric, [S. 1.], v. 1, n. 1, p. 1-14, jan. 1968.

BLIKSTEIN, I. Kaspar Hauser on a fabricação da realidade. 3. ed. São Paulo: Cultrix, 1990.

CAMPBELL, K. K.; JAMIESON, K. H. Form and genre in rhetorical criticism: an introduction. In: (Orgs.). Form and genre: Shaping rhetorical action. Falls Church: Speech Communication Association, 1978. p. 9-32.

CASTRO, B. D. de R. Apropriações institucionais do Twitter: uma análise sociorretórica dos perfis institucionais de IES piauienses. 2012. $238 \mathrm{f}$. Dissertação (Mestrado em Letras) - Centro de Ciências Humanas e Letras, Universidade Federal do Piauí, Teresina, 2012.

DEVITT', A. Writing genres. Carbondale: Southern Illinois University Press, 2004.

KOCH, I. V. Referenciação e orientação argumentativa. In: BENTES, A. C.; KOCH, I. V.; MORATO, E. M. (Orgs.). Referenciação e discurso. São Paulo: Contexto, 2005. p. 33-52

MAINGUENEAU, D. Análise de textos de comunicaşão. São Paulo: Cortez, 2001. MARCUSCHI, L. A. Gêneros textuais no ensino de língua. In: Produção textual, análise de gêneros e compreensão. São Paulo: Parábola, 2008. p. 146-224.

MILLER, C. R. Blogar como ação social: uma análise do gênero Weblog. In: Estudos sobre: gênero textual, agência e tecnologia. Reccifen: Ed. Universitária da UFPE, [2004] 2009. p. 61-92. Tradução: Judith Chambliss Hoffnagel et al.

. Gênero como ação social. In: Estudos sobre: gênero textual, agência e tecnologia. Recife: Ed. Universitária da UFPE, [1984] 2009. p. 21-44. Tradução: Judith Chambliss Hoffnagel et al.

. Questões da blogosfera para a Teoria de Gênero. In: Estudos sobre: gênero textual, agência e tecnologia. Tradução: Judith Chambliss Hoffnagel et al. Recife: Ed. Universitária da UFPE, 2009. p. 93-121.

MONDADA, L.; DUBOIS, D. Construção dos objetos de discurso e categorização: uma abordagem dos processos de referenciação. In: 
CAVALCANTE, M. M.; RODRIGUES, B. B.; CIULLA, A. (Orgs.). Referenciação. São Paulo: Contexto, 2003. p. 17-52.

SWALES, J. M. Genre analysis: English in academic and research settings. Cambridge: Cambridge University Press, 1990.

WILSON, J. Playing with politics: Political fans and Twitter faking in post-

broadcast democracy, 2011. Versão preliminar de artigo publicado na revista

"Convergence: The International Journal of Research into New Media

Technologies", nov. 2011, v. 17, n. 4, p. 445-461. Disponível em:

$<$ http://restlesscapital.net/wp-content/uploads/2011/05/Wilson-

ARTICLE.pdf $>$. Acesso em: 18 fev. 2012.

Recebido em: 30/07/12. Aprovado em: 30/10/12.

Title: The construction of objects of discourse in Fake Profiles of the Twitter

Authors: Francisco Alves Filho; Leila Rachel Barbosa Alexandre

Abstract: In this paper, taking as presupposition the idea that referenciation is a discursive process carried out during the construction of the text (MONDADA; DUBOIS, 2003; KOCH, 2005; MARCUSCHI, 2008), and also the understanding that discourse genres, according to their rhetorical and situational particularities, exert constraints for the referential processes, we aimed to analyze some peculiarities of the construction process of objects of discourse in posts produced in the fake profiles of Twitter, characterized by assuming the discursive logic of a celebrity and seeking to provoke fun and bumor to the Internet users. The corpus is composed of a set of examples of posts that circulated in fake profiles parodying Brazilian celebrities and were chosen according to the more evident incidence of referential construction. As a result we can say that fake both offers the perspective for the construction of objects of discourse mentioned in posts and is itself tributary of such a construction.

Keywords: Referenciation. Object of discourse. Fake profile of Twitter.

Titulo: La construcción de objetos de discurso em los perfiles fakes de Twitter Autores: Francisco Alves Filho; Leila Rachel Barbosa Alexandre

Resumen: En este articulo, tomando como supuesto la idea de que la referenciación es un proceso discursivo llevado a cabo durante la construcción del texto (MOND AD A; DUBOIS, 2003; KOCH, 2005; MARCUSCHI, 2008) y también el entendimiento de que los géneros del discurso, en función de sus particularidades retóricas y situacionales, ejercen condicionamientos para los procesos referenciales, objetivamos analizar algunas particularidades del proceso de construcción de objetos de discurso en publicaciones producidas en perfiles fakes de Twitter, éstos caracterizados por asumir la lógica discursiva de una celebridad y buscar provocar diversión y humor a los internautas. El corpus está compuesto por un muestrario de publicaciones que circularon en perfiles fakes parodiando celebridades brasileñas y fueron elegidas en función de la incidencia más evidente de la construcción referencial. Como resultado podemos afirmar que el fake tanto ofrece el punto de vista para la construcción de los objetos de discurso mencionados en las publicaciones como es él propio tributario de esa construcción.

Palabras-clave: Referenciación. Objeto de discurso. Perfil fake de Twitter.

Linguagem em (Dis)curso, Tubarão, SC, v. 12, n. 3, p. 765-792, set./dez. 2012 